\title{
Legalidades alternativas y tomas de tierras en una ciudad de la Patagonia Argentina
}

\section{Alternative legalities and land occupations in a city of Patagonia Argentina}

\author{
Santiago Bachiller ${ }^{1,2}$
}

\begin{abstract}
Resumen
Resultado de un trabajo etnográfico sobre ocupaciones de tierras en Comodoro Rivadavia (Chubut, Argentina), el artículo discute con las interpretaciones que reducen un fenómeno social complejo a una visión de las tomas como un simple "acto jurídico ilegal". Frente a los enfoques de la toma como una "usurpación", quienes ocuparon tierras esgrimen criterios que legitiman su accionar, los cuales, a su vez, se constituyen en una relación tensa con el orden jurídico formal. El objetivo del texto consiste en analizar dichas prácticas discursivas encaminadas a rebatir las lecturas dominantes que las descalifican a partir de la ilegalidad.

Buscando lidiar con los discursos hegemónicos que circunscriben las ocupaciones de tierras a un criterio legal, el primer apartado se organiza en torno al peso que la informalidad tuvo en la construcción histórica de las ciudades latinoamericanas. Tomando a Comodoro Rivadavia como caso testigo, en la segunda sección se dimensiona al Estado como promotor de la informalidad urbana. El tercer apartado conlleva el análisis empírico de los criterios de legitimidad en tanto respuestas populares a las visiones dominantes de las ocupaciones como "actos jurídicos ilegales". Finalmente, las conclusiones proponen una revisión de las principales líneas argumentativas desarrolladas a lo largo del trabajo.
\end{abstract}

Palabras claves: ocupaciones de tierras, ilegalidad, Estado, legalidades alternativas, criterios de legitimidad.

\begin{abstract}
As a result of an ethnographic work on land occupations in Comodoro Rivadavia (Chubut, Argentina), the article discusses interpretations that reduce a complex social phenomenon to a view of land occupations as a simple "illegal act". In opposition to the approaches of land occupation as a "usurpation," those who occupied lands hold criteria that legitimize their actions which, in turn, constitute a tense relationship with the formal legal order. The purpose of the text is to analyze these discursive practices aimed at countering the dominant readings that disqualify them from illegality.

Seeking to deal with the hegemonic discourses that circumscribe land occupations to a legal. criterion, the first section is organized around the weight that informality had in the historical construction of Latin American cities. Taking Commodore Rivadavia as a witness, in the second section the State is dimensioned as a promoter of urban informality. The third section conveys the empirical analysis of the criteria of legitimacy as popular responses to the dominant views of occupations as "illegal acts". Finally, the conclusions propose a revision of the main argumentative lines developed throughout the work.
\end{abstract}

Keywords: land occupations, ilegality, State, alternative legalities, legitimacy criteria.

Recibido: 13 marzo 2017. Aceptado: 25 septiembre 2017

1 Consejo Nacional de Ciencia y Tecnología de Argentina (CONICET), ARGENTINA. Email: santiago.bachiller@gmail.com

2 Universidad Nacional de General Sarmiento (UNGS). Juan María Gutiérrez 1150, B1613, Los Polvorines, Buenos Aires, ARGENTINA. Email: santiago.bachiller@gmail.com 


\section{Introducción}

El presente texto es resultado de un trabajo de campo etnográfico iniciado a principios de 2012, centrado en los asentamientos que surgieron mediante ocupaciones de tierras en Comodoro Rivadavia (provincia de Chubut, Patagonia Argentina). Si bien a lo largo de estos años frecuenté diversas zonas de la ciudad que responden a dichas características, focalicé mi trabajo de campo en un asentamiento conocido como Cancha Belgrano. Supe de la existencia de Cancha Belgrano durante una visita que realicé en 2012 a la Secretaría de Tierras y Hábitat. Mientras solicitaba información sobre asentamientos, una funcionaria me dijo: "Yo tengo un caso para vos. Es interesante... No se va a regularizar nunca, siempre van a vivir en la ilegalidad, porque están sobre un salitre". Luego me aclaró que se estaba refiriendo al "Macizo 48, Número 74". Pese a que la municipalidad había generado un informe técnico (que rechazaba cualquier posibilidad de regularizar el asentamiento aduciendo riesgo ambiental) y otro social (donde se registraba la existencia de unos 86 lotes tomados por distintas familias), en el mapa que me enseñaron la zona estaba pintada de blanco. Como sucedía con otros asentamientos de la ciudad, Cancha Belgrano no había sido contemplado en el mapa municipal; por el contrario, la cartografía oficial reflejaba una lógica dominante, donde aquello que era calificado como ilegal se equiparaba con un vacío cuya existencia no merecía el reconocimiento estatal.

El contexto en el cual surgió Cancha Belgrano fue el de un rápido crecimiento urbano y la consiguiente proliferación de tomas masivas de tierras, como resultado de fuertes procesos migratorios atraídos por la demanda de mano de obra del sector petrolero. Este asentamiento se formó en enero del ańo 2009, cuando unas 10 familias oriundas de Comodoro ocuparon tierras fiscales. El efecto contagio produjo que rápidamente otras familias tomasen los espacios aledaños disponibles. Actualmente Cancha Belgrano se compone de cinco manzanas en donde viven 110 unidades domésticas. En comparación con otros asentamientos, las particularidades de Cancha Belgrano consisten en que: a) sus habitantes nacieron en distintos puntos de Argentina, no así en otros países; b) se trata de personas que suelen tener empleo, aunque por lo general no calificado, por lo cual sus niveles de ingresos son modestos; c) son familias formadas por parejas jóvenes e hijos pequeños que experimentaron la ocupación como un intento por progresar respecto de un pasado reciente marcado por la precariedad residencial.

En este artículo pretendo analizar las consecuencias de interpretar un fenómeno social complejo mediante una visión simplista que reduce los procesos de tomas de tierras a un acto jurídico ilegal. Fruto de las lecturas hegemónicas basadas en la legalidad de los actos, una serie de categorías peyorativas etique$\tan$ a quienes residen en asentamientos informales como "ocupantes" o "intrusos", calificándolos como ciudadanos de segunda y justificando la inacción estatal relativa a la implementación de derechos básicos ligados al acceso a un hábitat digno. De tal modo, el objetivo de este trabajo supone examinar las prácticas discursivas de quienes ocuparon tierras, encaminadas a rebatir las interpretaciones del fenómeno como un acto jurídico ilegal. Frente a los enfoques de la toma como una "usurpación", estas personas esgrimen criterios que legitiman la ocupación y que se constituyen en una relación tensa con el orden jurídico formal.

El primer apartado se organiza en torno al peso que la informalidad ${ }^{3}$ tuvo en la construcción histórica de las ciudades latinoamericanas. Los debates académicos que allí se presentan nos recuerdan que la informalidad no ha sido una excepción, sino un principio básico de organización de la vida social y del desarrollo de nuestras ciudades. En el segundo apartado, y tomando Comodoro Rivadavia como caso testigo, se examina al Estado como uno de los principales promotores de la informalidad urbana. Aunque de manera sucinta, para comprender las dificultades de acceso al suelo que aquejan a una amplia masa poblacional y que impulsan a encontrar respuestas mediante la informalidad, en esta sección se considera la importancia del mercado constructor e inmobiliario en la configuración urbana de Como-

3 La ilegalidad es un concepto que suele aludir al orden jurídico, la noción de irregularidad se relaciona principalmente con el urbanismo, mientras que la informalidad remite a una tradición académica del campo de la economía. Debido a que tales discusiones superan los propósitos del presente artículo, dichos términos serán tratados como sinónimos. 
doro. El tercer apartado conlleva el análisis empírico de los criterios de legitimidad en tanto respuestas populares a las visiones dominantes de las ocupaciones como actos jurídicos ilegales. Dicha sección incluye un encabezado basado en las nociones de derecho subyacentes en la administración local de los conflictos barriales. Finalmente, las conclusiones proponen una revisión de las principales líneas argumentativas desarrolladas a lo largo del trabajo; asimismo, allí se presentan una serie de reflexiones articuladas en torno a la necesidad de ampliar las perspectivas que tradicionalmente circunscribieron la interpretación de las dinámicas de tomas de tierras al campo jurídico.

Antes de iniciar el desarrollo del artículo, quisiera dedicar unas líneas metodológicas. En cuanto a las técnicas de investigación, se realizaron entrevistas semiestructuradas a funcionarios de diversas dependencias municipales vinculadas con el objeto de estudio (Secretaría de Tierras, Dirección de Catastro, etc.), así como a representantes de instituciones con una significativa presencia territorial (Uniones Vecinales, en adelante UV; escuelas, etc.). Las entrevistas semiestructuradas focalizadas en los residentes de los asentamientos adquirieron un claro corte biográfico, cobrando especial relevancia el pasado residencial de los sujetos. El trabajo de campo también supuso la recolección de noticias sobre asentamientos generadas por los periódicos locales, informes oficiales $\mathrm{y}$, especialmente, el análisis de una documentación que refleja la comunicación tensa entre las autoridades municipales y los habitantes de Cancha Belgrano. Más que tratar dichas fuentes como "datos" que nos permiten acceder a una determinada "verdad", entiendo las mismas como una vía de acceso a las distintas y conflictivas representaciones sobre los espacios de relegación urbana en general, y sobre las nociones de derecho que sustentan los diversos actores en particular. Como sucede en toda etnografía, la observación participante fue una técnica de investigación prioritaria. En tal sentido, el registro de las asambleas barriales me permitió indagar la evolución de las prácticas y discursos de los residentes encaminados a transformar su espacio residencial en un "barrio". Gracias a la organización y al esfuerzo de los vecinos, el asentamiento consiguió ciertos avances a nivel de servicios e infraestructura; sin embargo, aún no logró que la municipalidad mensure los lotes, motivo por el cual no progresó en lo que respecta a la obtención de títulos de propiedad. En definitiva, el estudio de los procesos de construcción social del espacio residencial implicó entender la ocupación de tierras como un campo de disputa marcado por las diferentes maneras de concebir el derecho. Así, las tensiones y negociaciones entre las autoridades municipales y los habitantes del asentamiento reflejaron el encuentro conflictivo entre una estrategia estatal encausada a definir las tomas de tierras a partir de la legalidad, y una respuesta popular para la cual el derecho no se circunscribe a un orden jurídico, sino que se amplía vinculándose con un sentido de justicia que legitima la ocupación.

\section{Legalidades alternativas: el peso de la informalidad en la expansión de la ciudad latinoamericana}

A mediados del siglo XX, la mayoría de los países latinoamericanos comenzaron a vivir un fuerte proceso de urbanización que nunca se revirtió. Millones de personas poblaron las periferias de las ciudades; desde entonces, solemos hacer referencia a la existencia de dos ciudades: la formal y la informal, la legal y la ilegal (Rincón, 2006). Según Fernandes (2008), el 75\% de la población de nuestro continente vive en ciudades, y al menos uno de cada cuatro ciudadanos ha accedido a la tierra urbana y/o a la vivienda a través de procesos informales. Es la forma latinoamericana de crear espacio urbano: una producción de ciudad que se genera incumpliendo los estándares y criterios establecidos por la legislación civil y urbanística.

El peso que la informalidad tiene en el desarrollo urbano se relaciona directamente con los obstáculos en el acceso a la tierra que afectan a los sectores populares. Estas dificultades pueden rastrearse en diversos procesos históricos como el colonialismo, la posterior avanzada militar republicana y el reparto de las "tierras de indios". Actualmente, las dificultades de acceso al suelo urbano se asocian con las condiciones de urbanización capitalista que combinan un régimen de propiedad privada del suelo con dispositivos que permiten la producción y acumulación de rentas extraordinarias mediante el proceso de urbanización (Cravino y Fernández Wagner, 2006; 
Catenazzi y Reese, 2010). En América Latina, el acceso al mercado legal de la vivienda suele restringirse a las élites o a las clases medias, y ello guarda relación con distintos factores: el permanente aumento de los precios de los lotes en relación con los ingresos de la población; la inexistencia de sub-mercados de suelo específicos para los sectores populares; las exigencias normativas restrictivas; la falta de créditos accesibles para la población pobre; la presencia de altas tasas inflacionarias que convierten el patrimonio inmobiliario en la inversión más rentable; el déficit histórico a nivel de políticas sociales de vivienda; un mercado del suelo cuyo funcionamiento se limita a los beneficios que los agentes privados pretenden obtener, etcétera (Clichevsky, 2004). Por consiguiente, existen tres grandes lógicas de coordinación social de acceso al suelo urbano. El Estado y el mercado representan las formas convencionales de acceso al espacio urbano; se trata de instituciones cuyo funcionamiento se basa en un determinado marco normativo. La tercera vía ha sido calificada como la "lógica de la necesidad" (Abramo, 2009). Esta lógica sortea los marcos clásicos de acceso al suelo urbano, opera mediante un mercado informal que escapa de los sistemas de control tradicionales del Estado y del derecho. Para muchos ciudadanos el acceso legal al suelo urbano es inalcanzable, por lo cual la informalidad se convierte en el modo predominante de acceso a la ciudad (Cravino y Fernández Wagner, 2006).

Al considerar el peso de la ilegalidad en la producción histórica de nuestras ciudades, tomamos conciencia de que la expansión de "la ciudad informal" no es un fenómeno nuevo ni excepcional; su generalización evidencia que es un error entender a la misma como una anormalidad, como una desviación de un modelo universal de crecimiento urbano. Tal como sostiene Rincón (2006),

\section{[...] no se trata solo de pensar la ilegalidad} urbana como un ejercicio individual de no acatamiento de la norma, más bien se trata de entender que la tensión entre legalidad e ilegalidad incorpora fundamentos más amplios de la experiencia social, esta tensión se inscribe en los principios organizadores de la vida colectiva y específicamente en la natu- raleza de la transformación del fenómeno urbano. Pensar la ilegalidad en la producción de la ciudad nos aproxima a una relectura de la ciudad y sus prácticas sociales como centro de reflexión (p. 676).

El sistema normativo divide el campo social en dos sectores supuestamente bien diferenciados: el legal y el ilegal. Mediante esta lógica que delimita un adentro de un afuera, la ley configura territorios de ciudadanía plena o restringida; a partir de entonces, la ilegalidad y/o la informalidad se espacializa. No hay nada natural en la definición de ilegal; por el contrario, es el Estado el que ubica a los residentes de determinados espacios urbanos (asentamientos, villas, favelas, etc.) en dicho campo infravalorizado (Casabona y Gúber, 1985).

La ilegalidad ha sido un eje disparador de intensas discusiones en el ámbito académico. Al interior de dichos debates, la noción de propiedad ocupó un lugar central. En opinión de Clichevsky (2004), el derecho de propiedad constituye el mayor obstáculo a la seguridad de la tenencia. Tengamos presente que la producción de nuestras ciudades se encuentra condicionada por la tensión existente entre el derecho constitucional de acceso a una vivienda digna y el derecho real de propiedad (Canestraro, 2009). La concepción del suelo como una simple mercancía deja en situación de ilegalidad a la mayor parte de la población que, en nuestro continente, no puede acceder a la vivienda gracias a sus ingresos. Simultáneamente, la ilegalidad/informalidad atrapa a estas poblaciones en una contradicción que, inevitablemente, deriva en un conflicto: deben violar la propiedad privada para acceder a la misma (Cravino y Fernández Wagner, 2006). De tal modo, investigadores como Cravino (2009) definieron los asentamientos como fragmentos de ciudad sin estatus de ciudad. Tal carencia de estatus implica una forma específica de acceso a la ciudad marcada por la falta, o la atenuación, de derechos de ciudadanía. A su vez, la calificación de la toma de tierras como un acto ilegal se asocia con otra serie de irregularidades que se refuerzan mutuamente: la precariedad de la vivienda, la disposición del espacio, el usufructo clandestino de los servicios, el no pago de los impuestos municipales, la condición 
de "indocumentados" de los residentes procedentes de otros países, las actividades de subsistencia de los comercios que no cuentan con habilitación municipal, etcétera. En definitiva, cuando prioriza los criterios jurídicos, el discurso estatal reconoce la existencia de los espacios que nacieron mediante tomas masivas de tierras, pero lo hace tildando a esta población de "intrusos" que transgreden las leyes y normas morales; entonces, surgen categorías peyorativas como las de "ocupantes" o "usurpadores", las cuales dejan un estrecho margen de negociación y réplica a quienes viven en sitios socialmente desacreditados.

Las denominaciones más frecuentes que reciben los barrios pobres periféricos suelen remitir al orden jurídico. Los términos irregulares, informales, extraoficiales o ilegales nada indican sobre las características físicas o económicas de estas áreas, sino que refieren a una relación problemática con el orden jurídico vigente. En ocasiones, estas denominaciones son replicadas por una literatura académica que, al transformar dichos principios legales en criterios analíticos, termina reforzando los argumentos que conciben la irregularidad como un atributo intrínseco de los procesos de formación de los asentamientos populares (Azuela, 1993). Operando de tal modo, se olvida que nada es ilegal en sí mismo, sino que la ilegalidad es una cualidad que se define desde el Estado. Tampoco se comprende que los espacios nunca son legales o ilegales, pues solo la acción humana puede ser calificada de tal modo. Finalmente, al tildar un asentamiento como irregular, todos los residentes quedan incluidos en una misma categoría estigmatizante; tal lectura del fenómeno social legitima la negativa estatal de efectivizar el derecho a residir en un hábitat digno.

En los debates académicos sobre el peso de la ilegalidad en la producción de la ciudad, la regularización de los asentamientos merece un párrafo aparte. Estas discusiones tuvieron su epicentro durante las décadas de 1980 y 1990 y giraron en torno a las condiciones de legalidad, dando por hecho que la entrega de títulos de propiedad garantizaría la inserción de los pobladores en el sistema. El economista peruano Hernando de Soto fue el pope de premisas ideológicas que sostenían que el derecho a la propiedad sería el dogma que explicaría el "triunfo" del ca- pitalismo; según estos enfoques, los Estados debían financiar la reducción de la pobreza convirtiendo lo informal en formal (Fernández Wagner, 2008). De modo similar, los países en vías de desarrollo debían "garantizar el acceso al crédito, lo que sería posible a través de programas de legalización bajo la forma de la propiedad individual plena de los asentamientos informales" (Fernandes, 2008, p. 34).

La discusión sobre los programas de regularización excede las posibilidades de este texto, por lo cual me limito a señalar algunos de los cuestionamientos más significativos a dichos paradigmas. En primer lugar, estas propuestas reforzaron una ideología que dio por sentado que la integración se reduce a lo económico, que sacralizó la propiedad, y que nunca comprendió las dinámicas informales. En segunda instancia, la regularización generó un mercado de subalquiler de habitaciones que, lejos de beneficiar a los inquilinos, terminó incrementando las diferencias sociales. Al respecto, autores como Cravino (2009) advierten del peligro inherente a crear una amplia subclase que se sienta explotada y que se muestre hostil frente a quienes son concebidos como los propietarios de las habitaciones donde residen. Finalmente, estas políticas frecuentemente generaron áreas legalizadas, pero no necesariamente sostenibles. Y ello fue así pues regularizar no es sinónimo de combatir la pobreza; por el contrario, comprender la complejidad de las dinámicas informales supone entender que la integración socio-espacial trasciende la entrega de títulos de propiedad, pues incluye dinámicas más amplias ligadas con los modos en que determinadas zonas se conectan a nivel material, de servicios, infraestructura y simbólicamente con el resto de la ciudad (Cravino y Fernández Wagner, 2006; Fernandes, 2008).

La necesidad de discutir cómo la norma se estructura sobre la base del principio jurídico de la propiedad condujo a una proliferación de estudios organizados alrededor de la noción de derecho a la ciudad. Mediante dicho concepto se intentó trascender la visión jurídica, incluyendo una dimensión política y cultural sobre la propiedad y los accesos y usos de la ciudad. Esta noción remite a los estudios de Lefebvre de los años sesenta y setenta; en Argentina fue recuperada en la década del ochenta por Oszlak (1991), pero recién a fines de los noventa su uso se 
tornó masivo. En los debates urbanos, la categoría de derecho a la ciudad giró en torno a una serie de ejes: cómo el Estado se rige por instrumentos jurídicos que fomentan las condiciones injustas de acceso a la tierra; la producción informal de la ciudad por medio de mecanismos sociales que están por fuera del derecho positivo estatal; la fuerte disociación entre la ley prescrita y su aplicación territorial, lo cual conlleva a entender las ciudades como una hibridación de legalidades/ilegalidades, etcétera. Por otra parte, durante los últimos ańos la noción de justicia espacial comenzó a ganar territorio al interior de las ciencias sociales latinoamericanas. Como ocurriera con el concepto de derecho a la ciudad, la justicia espacial es deudora del pensamiento crítico, siendo Edward Soja el pionero en el uso de la nueva categoría analítica. En Argentina la discusión sobre la justicia espacial se expresó a partir de los siguientes ejes (Salamanca, Pizarro y Fedele, 2016): la violencia y la movilización social como disputas y efectos de la justicia espacial (bajo este ítem proliferaron los estudios sobre el terrorismo de Estado durante la última dictadura militar, pero también indagaciones sobre las prácticas violentas asociadas con las políticas neoliberales de seguridad); las políticas urbanas (aquí prosperaron los ensayos sobre la desigualdad y las políticas públicas vinculadas con la producción del espacio urbano); la relación entre justicia y medio ambiente (con énfasis en las discusiones sobre la ecología política y las tensiones espaciales derivadas del extractivismo).

Para este trabajo, es de especial interés la propuesta de Duhau y Giglia (2004), quienes entienden el orden urbano como la regulación social de la apropiación y uso de los espacios y bienes constitutivos de la ciudad. En este enfoque, el orden excede al conjunto de reglas formales del ámbito jurídico, incluyendo las convenciones sociales. Apartándonos de las perspectivas legalistas, nos detenemos en los conocimientos prácticos que nos indican para qué sirven, cómo se usan ciertos objetos presentes en determinados contextos, cuáles son los comportamientos prohibidos y cuáles los prescriptos en los diferentes escenarios urbanos, etcétera. Se trata de las creencias y puntos de vista respecto de las actividades y usos del espacio público y privado que en distintos contextos son válidos en términos morales, prácticos o de estatus social; representaciones que en ciertas ocasiones son objeto de regulaciones formales, mientras que en otras se rigen por prácticas espaciales aceptadas socialmente y que se encuentran en oposición a la norma formalmente vigente. Dichas prácticas repetidas en el espacio abren una brecha al orden jurídico pues, de hecho, son percibidas como similares a la norma.

Cuando reconocemos que la ciudad es producida por diversos urbanismos, entonces lo que el Estado denomina como ilegalidad puede reconvertirse en ciertos criterios de legitimidad. Los mismos evidencian un urbanismo tácito que se presenta en una relación tensa con los principios legales articulados en torno a la propiedad. El derecho no es el único que regula como norma positiva los procesos de apropiación y uso del suelo. Por el contrario, en un mismo espacio urbano pueden coexistir una pluralidad de regulaciones en permanente interacción y construcción mutua que desencadenan una serie de racionalidades normativas o prácticas producidas y transformadas socialmente a través del tiempo, que circulan en la sociedad, que ejercen un control de la acción social dentro del territorio, y que aspiran a tener el monopolio de la regulación (Souza Santos, 1995; Rincón, 2006). Las diferentes racionalidades normativas ejercen controles territoriales espacializados que marcan condiciones de ocupación, usos y transformaciones del territorio, para configurar tipos de legalidades urbanas que emergen en territorios específicos.

Las diversas racionalidades y sus respectivas territorialidades no desconocen el papel central que la legalidad estatal tiene en la definición de límites, marcos y lenguajes; de hecho, las racionalidades que surgen en los territorios declarados como informales solo pueden entenderse con relación a la construcción estatal de la legalidad aplicada a determinados espacios urbanos (Souza Santos, 1995; Rincón, 2006). Pero en este punto es preciso advertir lo siguiente: las normas jurídicas en sí mismas carecen de fuerza como para imponerse unívocamente sobre los procesos sociales. Por consiguiente, lo determinante es el sentido jurídico que los propios actores dan a sus prácticas y a las de los demás. Vale la pena repetirlo: la irregularidad no existe en sí misma, sino como una forma de representar las relaciones sociales. Consecuentemente, la manera en que los 
residentes de un asentamiento perciben el acceso a la tierra implica siempre una definición jurídica que no necesariamente coincide con las normativas formales; así, los diversos modos de legitimar el control sobre la tierra conllevan un conjunto de representaciones normativas por medio de las cuales los actores reconocen su situación en una relación social en términos jurídicos (Azuela, 1993).

En Latinoamérica, distintos trabajos han discurrido en torno a cómo las nociones de derecho se expresan en los procesos de producción de asentamientos. En tal sentido, un conjunto de estudios argumenta sobre la existencia de múltiples sensibilidades legales presentes en las dinámicas de tomas de tierras (Azuela, 1993; Souza Santos, 1995; Rincón, 2006). En Argentina, Canestraro (2011) examinó las tomas de tierras como un proceso de fetichización de las normas mediante el cual incluso aquellos discursos más críticos quedan limitados al encuadre que sugiere la normatividad estatal. Asimismo, Fava (2014) indagó cómo los criterios de justicia y legitimidad en el acceso al suelo se ven condicionados por definiciones restrictivas de la categoría de "vecino" en oposición a la de "ocupante". Ostuni y Van Gelder (2008) retomaron los debates académicos sobre la propiedad legal, preguntándose si las políticas de titulación responden a las necesidades de los residentes de los barrios informales. Recuperando el punto de vista de los habitantes, la propuesta de estos investigadores supone analizar la relación entre el acceso a la propiedad legal de los terrenos, y la racionalidad de las asignaciones de recursos económicos por parte de las familias a la hora de realizar mejoras en sus viviendas. Por otra parte, Núñez (2010) se pregunta por la manera en que la justicia distributiva se manifiesta en las prácticas cotidianas asociadas con la implementación de políticas asistencialistas en cinco barrios de Quilmes y cómo, a su vez, estos principios de justicia distributiva influyen en la evolución de los criterios que justifican la ocupación de tierras.

En el presente se observan cambios relevantes en lo que respecta a la producción social del hábitat popular, que se manifiestan en la verticalización, densificación, mercantilización y en el surgimiento de nuevos actores inmobiliarios que operan al interior del mercado informal. En ciudades como Buenos Aires, estas tendencias implicaron la proliferación de un mercado informal de viviendas basado en la venta de cuartos o departamentos de un ambiente (por lo general producto de la subdivisión de una vivienda y/o de una pequeña nueva construcción), y especialmente en la construcción de cuartos para alquilar. Actualmente, el alquiler de una habitación suele ser la modalidad típica de acceso para los sectores populares "recién llegados" a la ciudad. De hecho, la principal fractura en la sociabilidad barrial está signada por un mercado inmobiliario informal que genera dos grupos con intereses antagónicos y con un estatus social muy diferente: quienes son percibidos como propietarios, aun cuando no tengan un título de propiedad que acredite tal condición, son equiparados a ciudadanos de primera, mientras que los inquilinos serían ciudadanos de segunda categoría. Tal es así que algunas de las tomas de tierras recientes fueron protagonizadas por inquilinos de villas miseria con serias dificultades para pagar los precios exorbitantes de un mercado de habitaciones marcado por la precariedad (Fava, 2014). Para los fines del presente trabajo, es especialmente relevante el análisis que Cravino (2009) realiza sobre el modo en que el mercado informal se expande por los asentamientos, construyendo un urbanismo tácito basado en un cuerpo de normas locales para la convivencia y los conflictos entre vecinos que interpela a la legalidad oficial. Estas legalidades alternativas se desarrollan incrustadas en relaciones sociales previas, como los vínculos de parentesco o las redes de connacionales entre inmigrantes; es por ello que las transacciones del mercado inmobiliario informal suponen una fusión entre las modalidades de reciprocidad y los preceptos que rigen cualquier mercado. Consecuentemente, la ilegalidad de las transacciones del mercado inmobiliario no necesariamente supone ilegitimidad, ya que se sustentan en dicho orden jurídico local alternativo.

En resumidas cuentas, el análisis de las prácticas colectivas territoriales lleva a sostener que las fronteras que delimitan lo legal de lo ilegal no son tan claras. Parafraseando a Rincón (2006, p. 677), diríamos que la pregunta central se desplaza de la ilegalidad (la producción estatal de un dentro/fuera del ordenamiento jurídico) hacia los conflictos y negociaciones que representan la combinación de territorialidades legítimas y legales, legales pero no legítimas, $o$ 
ilegales y legitimadas socialmente, las cuales conllevan la reproducción social de espacialidades ilegales, pero también de espacialidades socialmente legalizadas.

\section{El Estado como promotor de la ilegalidad en Comodoro Rivadavia}

Comodoro Rivadavia es una ciudad patagónica de unos 250 mil habitantes, localizada en el corazón de una de las mayores cuencas hidrocarburíferas de Argentina. La historia de Comodoro se encuentra determinada por la producción de petróleo. Tanto es así que los períodos de mayor crecimiento urbano coincidieron con los denominados booms petroleros, coyunturas donde el precio internacional de barril de petróleo se dispara incentivando la demanda de mano de obra, la llegada masiva de migrantes atraídos por las oportunidades laborales, el encarecimiento del precio del suelo urbano y, finalmente, las tomas de tierras (Bachiller, Baeza, Vázquez, Freddo y Usach, 2015).

No casualmente, la primera gran transformación en la espacialidad urbana se produjo cuando el presidente Arturo Frondizi (1958-1962) facilitó la explotación de hidrocarburos a empresas privadas nacionales y multinacionales. Entonces, el arribo de miles de migrantes procedentes del sur de Chile y del noroeste argentino (NOA) se materializó en la ocupación masiva de tierras en las laderas de los cerros de la zona sur de la ciudad. Coincidiendo con un nuevo boom petrolero, entre 2005 y el año 2010 la ciudad vivió otro proceso de crecimiento vertiginoso. Si comparamos la evolución poblacional entre los censos nacionales de 2001 y de 2010 observamos que Comodoro incrementó su población un 29\%; se trata de un porcentaje muy superior al crecimiento del país y de la provincia, que fueron del $10 \%$ y del $23 \%$, respectivamente. Dicho crecimiento no se correspondió con una densificación de los barrios preexistentes y consolidados de la trama urbana, sino principalmente con la expansión hacia los espacios periféricos mediante ocupaciones de tierras y la autopromoción en la construcción de las viviendas (Bachiller et al., 2015).

Los precios prohibitivos de una ciudad sobredeterminada por la industria petrolera representan un factor fundamental para comprender las recurrentes tomas de tierras en la historia local. En la ciudad patagónica el costo de vida es uno de los más altos del país: si en 2013 en la provincia de Chubut una familia tipo precisaba de $5.787,98$ pesos (1.083 dólares) para no ser pobre, en Comodoro dicha canasta familiar, que no calcula los precios relacionados con la vivienda, se disparaba a los $9.330,85$ pesos (1.747 dólares). A su vez, las desigualdades se intensifican en lo que respecta al acceso al suelo y la vivienda, ya que los precios del mercado inmobiliario corren en sintonía con la renta petrolera. ${ }^{4}$ En enero de 2015, el alquiler de departamentos de uno o dos ambientes oscilaba entre los 3000 y 8000 pesos (561 y 1498 dólares), uno de los valores más altos del país. En la localidad chubutense los alquileres de inmuebles bailan al ritmo del petróleo, y ello es así pues el 70\% de las propiedades del mercado son cooptadas por las operadoras petroleras. Por otra parte, las empresas constructoras y/o inmobiliarias no cubren todo el territorio, sino que se focalizan en las áreas que les garantiza una mayor rentabilidad, sin preocuparse por la edificación en los barrios populares. Por último, es preciso añadir el lugar mínimo del sistema de créditos hipotecarios en el país en general, y en la región en particular. Este relato sintético del modo en que opera el mercado inmobiliario permite comprender el carácter clasista que determina el acceso al suelo urbano y la vivienda.

Tras analizar la historia local, queda en claro que el Estado es el gran generador de informalidad urbana. En primer lugar, debido a la insuficiente cantidad de viviendas oficiales construidas, a principios del 2013 existían más de 7 mil expedientes solicitando terrenos y solo unos 2.200 lotes disponibles (Bachiller et al., 2015). Asimismo, según fuentes periodísticas del 2016 (El Patagónico, 28.08.2016), en Comodoro habría unas 3 mil ocupaciones de tierras. ${ }^{5}$ Ahora bien, el principal constructor de viviendas estatales

4 El salario promedio del total de los sectores en la ciudad en 2013 rozaba los 8 mil pesos (1.496 dólares), mientras que las remuneraciones en el sector petrolero duplicaban dicha cifra (Bachiller et al., 2015).

5 Cabe aclarar que esta cifra no contempla los asentamientos que recientemente consiguieron un reconocimiento estatal, aunque continúan padeciendo todo tipo de carencias a nivel de infraestructura, servicios urbanos y/o conectividad con el resto de la ciudad. 
en la ciudad es el Instituto Provincial de la Vivienda (en adelante IPV); entre fines de 2011 y mediados de 2014, el IPV entregó 422 viviendas en Comodoro Rivadavia (Bachiller et al., 2015). Consecuentemente, cuando prima la lógica de mercado y las políticas habitacionales son insuficientes, miles de personas deben apelar a la informalidad como principal modo de afrontar sus necesidades residenciales.

Todas las personas entrevistadas, ya sean funcionarios municipales, empresarios de la construcción y/o de inmobiliarias o pobladores de asentamientos, coincidieron en diagnosticar una histórica ausencia estatal en materia de planificación urbana. Habría que matizar estas afirmaciones, señalando que la ciudad posee un pasado de planificación, aunque la misma nunca fue urbana, sino que se limitó a garantizar la extracción y circulación de hidrocarburos. Si el Estado promueve la informalidad es también como consecuencia de la falta de un ordenamiento territorial general. Aunque escasos, existen algunos antecedentes de intentos de proyección urbana (un ejemplo sería el Plan de Desarrollo Urbano Ambiental de 1999). No obstante, los mismos siempre terminaron en letra muerta o resultaron obsoletos ante una realidad urbana muy dinámica. Asimismo, las ordenanzas sobre acceso y uso de la tierra fiscal representaron la legislación que intentó contener y regular las ocupaciones de tierras. Desde la Resolución 176 promulgada en 1956 (la primera de todas) hasta el presente, numerosas ordenanzas se han ido sucediendo. Algunas de ellas promocionaron la venta de tierras fiscales, muchas tuvieron un claro tono punitivo, mientras que otras apuntaron a facilitar el desarrollo económico y el bienestar de los sectores populares; por consiguiente, la ausencia de un ordenamiento territorial también guardó relación con una evolución de las ordenanzas signada por políticas contradictorias. Finalmente, la insuficiencia de los marcos político-institucionales de ordenamiento territorial se expresaron en una auténtica política municipal de "excepcionalidad" ante las situaciones de irregularidad urbanística; es preciso recordar que la proliferaron de resoluciones municipales que condonaron "excepcionalmente" a innumerables casos de violación de la legislación vigente no se limitaron a amnistiar a ciertos asentamientos, sino que incluyeron edificios que excedían la altura permitida, la ampliación de viviendas o comercios sin la corres- pondiente aprobación municipal de los planos arquitectónicos, a empresas que se instalaron sin permiso en tierras fiscales, etcétera.

Las explicaciones sobre las ocupaciones de tierra no se limitan a una dimensión material; por el contrario, la cuestión cultural cobra importancia, ya que las tomas masivas se inscriben en una tradición arraigada en el tiempo, según la cual ése es el modo específico en que los sectores populares acceden al suelo urbano. Las primeras aproximaciones del Estado nacional a la Patagonia se encuadraron bajo una lógica de "desierto a poblar" (por migrantes europeos, negando así la presencia y justificando el exterminio de las comunidades indígenas); durante décadas, la ocupación del suelo en una "zona de frontera" fue visualizada como una forma de "hacer patria" frente a la "amenaza chilena". Tal es así que las personas entrevistadas que tomaron tierras en los ańos cincuenta y sesenta sostienen haberse instalado en un espacio al cual evocan como "vacío", como tierra "disponible". A su vez, si bien la tolerancia histórica frente a la ocupación directa no necesariamente se tradujo en un reconocimiento legal de la posesión, lo cierto es que los desalojos masivos no fueron habituales en la historia local. La ocupación de tierras remite a las épocas fundacionales de la ciudad, así como se trata de una práctica extendida que no se limita a los sectores populares. Durante sus primeras décadas de vida, la ciudad se expandió hacia la zona norte mediante la construcción de campamentos empresariales (por lo general petroleros) que solicitaron permisos para afincarse en tierras fiscales. Las respuestas tardaron años en llegar, pues la oficina que regulaba tales asuntos se localizaba en Buenos Aires, a casi 2 mil kilómetros de distancia; por consiguiente, es posible afirmar que los orígenes de dichos campamentos también estuvieron ligados con la ocupación de tierras. De modo similar, a mediados de la década del 2000, empresarios locales tomaron tierras y edificaron sus industrias en una amplia zona perteneciente a radio nacional. Las "tomas VIP" (tal como una funcionaria municipal calificó a estas ocupaciones, apelando irónicamente a la sigla Very Important People) gozaron de la venia del gobierno local y no recibieron el mismo tratamiento mediático ni despertaron el mismo rechazo por parte de la población, en comparación con lo que sucedió ante la expansión de casillas precarias (Bachiller 
et al., 2015). En resumidas cuentas, la ocupación "ilegal" de tierras no necesariamente es sinónimo de pobreza, aunque su asunción como conflicto sí es diferencial (Canestraro, 2009).

Como sostiene Azuela (1993), no son las leyes sino las burocracias locales las que suelen decidir sobre la situación de "ilegalidad"; de esta discrecionalidad burocrática depende el derecho a la ciudad. El Estado reconoce constitucionalmente tanto el derecho a la propiedad como el acceso a la vivienda, con lo cual los gobiernos y los poderes judiciales locales son los que interpretan el código en función de sus creencias. En un presente marcado por la escasez de tierras disponibles y la consiguiente competencia por el espacio urbano, y a contracorriente de lo estipulado por la tradición urbana local, la municipalidad es el principal actor que fomenta una lectura jurídica del fenómeno. Hoy en día, la Secretaría de Tierras posee un mayor control del terreno respecto de épocas pasadas, por lo cual sus políticas se focalizan en impedir nuevas ocupaciones. Por otra parte, y a pesar de los discursos de mano dura, en el presente la práctica estatal más común frente a los espacios que surgieron a partir de tomas es una desidia absoluta. Los asentamientos no son desalojados, sino más bien abandonados en una situación de precariedad condenatoria.

El Estado no es una institución homogénea ni de una neutralidad aséptica, sino que está plagado de contradicciones internas que, en ocasiones, son aprovechadas por los grupos sociales para inclinar la balanza a su favor ante un conflicto urbano. Así, mientras el mismo gobierno municipal fomentaba un discurso represivo, entre 2009 y 2011 la Secretaría de Tierras y Hábitat fue presidida por una arquitecta que intentó imprimir un sello más progresista a su gestión, implementando metodologías que no siempre se adecuaban a los códigos urbanos. Es lo que ocurrió con la "guarda y custodia", una figura que conllevaba entregar la parcela a la familia que la había ocupado mientras la mensura avanzaba en términos administrativos, a cambio de que el vecino cercase el terreno y evitase nuevas ocupaciones en la zona. De tal modo, a pesar de que la calificación general de ilegalidad persistía, en la vida cotidiana los residentes de los asentamientos lograron cierta seguridad en la tenencia de la tierra gracias a fórmu- las jurídicas que la burocracia local utilizó para la resolución de los conflictos urbanos (Azuela, 1993). Finalmente, debido a presiones políticas, la arquitecta debió renunciar; con su dimisión la figura legal de la "guarda y custodia" desapareció, aunque, de algún modo, continuó amparando a quienes habían recibido dichos certificados estatales. Es lo que puede observarse en el siguiente fragmento de entrevista, donde la directora de Catastro critica la gestión anterior de la Secretaría de Tierras (6 junio 2012):

[L]a gente, el lugar que encontró lo ocupó y de-
trás lo fueron como blanqueando. Por supues-
to, con documentos que podrímos decir que
no tienen ninguna validez legal, como entregas
en guarda y custodia, que de alguna manera
convalidaban esa ocupación. Hoy no tenemos
una usurpación de la tierra en el real sentido
de la palabra, sino que hubo ocupaciones que
de hecho el Estado las convalidó estos años pa-
sados. Así que cuando de pronto yo atiendo hoy
a la gente y le digo usted usurpó, enseguida me
sacan una entrega en guarda o custodia y me
dicen no, a míme dieron el terreno.

Si el Estado es el gran generador de informalidad urbana es también debido al modo en que promueve una concepción de acceso al suelo que se restringe a la propiedad privada individual. La falta total de regulación estatal en materia de acceso al suelo urbano permitió que el mercado constructor e inmobiliario se moviese a sus anchas. Más aún: el Estado local naturaliza y reproduce los criterios del mercado. Así, la Secretaría de Tierras vende lotes fiscales aproximadamente a un $40 \%$ del valor de mercado, pero el precio se encuentra determinado por la zonificación urbana impulsada desde el mercado inmobiliario. Es decir, la municipalidad no interviene buscando disminuir las desigualdades territoriales que el mercado genera, sino que establece el precio del lote fiscal dando por válidos los criterios espaciales del propio mercado, a los cuales luego les resta un $40 \%$ de su valor.

El Estado promueve la informalidad sobre la base de criterios que exceden a la propiedad. Es lo que ocurrió con las sucesivas ordenanzas municipales que regulan el acceso al suelo fiscal y que, desde la 
década de 1950, han sido organizadas en función de un sistema de puntaje que otorga prioridades a los argentinos sobre los extranjeros, para luego discriminar entre los argentinos de acuerdo al tiempo de residencia en la ciudad. La categoría de "nacidos y criados" es central en la vida social local; la misma presupone que hay o debería haber ciertos privilegios para aquellos que son "verdaderamente" del lugar (Baeza y Grimson, 2013). Dicho sentido común se materializa en estas normativas municipales, las cuales sostienen que el tiempo de residencia es un criterio básico en la legitimación de las distancias sociales, reforzando, de tal modo, el orden social existente. Es lo que ocurrió por ejemplo con la Ordenanza Municipal 7297/00, que reservó un $70 \%$ de los lotes disponibles en la ciudad a los "hijos del barrio"; bajo tal rótulo fueron definidos quienes podían demostrar ser familiares directos de los vecinos que ostentaban una antigüedad superior a los 10 años de permanencia en el barrio. En estos discursos, las concepciones de derecho se localizan y restringen tanto que bordean lo ridículo: en un contexto marcado por el incremento en la demanda en paralelo a la escasez de tierra urbana disponible, para estas lógicas el derecho a la vivienda no debería centrarse en los extranjeros ni en los argentinos nacidos en otras provincias ni en los chubutenses oriundos de otras localidades, y ya ni siquiera en otros comodorenses, sino que debería constreñirse a los jóvenes que nacieron en determinado barrio (Bachiller et al., 2015). En definitiva, los supuestos que subyacen en estas ordenanzas municipales de acceso al suelo sostienen que la antigüedad debería ser el principio fundamental que regule la asignación de recursos y privilegios; estas medidas son las que promueven que los "recién llegados", más aún si son extranjeros, visualicen las tomas de tierras como una alternativa para afrontar sus necesidades habitacionales.

En ocasiones, es el propio Estado el que opera desde la ilegalidad. En el trabajo de campo pude constatar "la quema de ranchos" como la cara oculta de las políticas de tierras implementadas durante los primeros meses de la gestión municipal de Di Pierro (2011-2015). Es decir, bajo las órdenes de las más altas esferas municipales, ciertas patotas rentadas incendiaron las viviendas precarias de un asentamiento como un ejemplo aleccionador encaminado a desincentivar la proliferación de tomas de tierras.
Asimismo, la potestad de entregar lotes, construir viviendas y urbanizar barrios permite acumular un enorme poder tanto en lo que respecta a la gestión de recursos económicos como a la generación de lealtades políticas. Consecuentemente, no debemos extrañarnos ante las decenas de denuncias por corrupción que involucraron a dichas dependencias a lo largo de la historia local. ${ }^{6} \mathrm{~A}$ su vez, el capital relacional tradicionalmente jugó un papel central en la selección de destinatarios de las escasas políticas de viviendas para Comodoro Rivadavia. Las clases medias suelen aprovechar sus contactos personales y así terminan convirtiéndose en los beneficiarios de las entregas discrecionales. Por último, y como se constatará luego, rotular un espacio urbano como ilegal genera una esfera de ambigüedad que posibilita resignificar los derechos de ciudadanía en términos de asistencialismo, clientelismo y subordinación.

En definitiva, la constitución de criterios que legitiman las tomas de tierras se ligan con las dificultades de acceso legal al suelo urbano que padecen los sectores populares. Tal como veremos en el próximo apartado, dichos criterios de legitimidad suponen una relación conflictiva y ambivalente con los principios legales en general, y con la noción de propiedad en particular.

\section{Criterios de legitimidad, o las respuestas populares ante las lecturas jurídicas de la ocupación como un acto ilegal}

En la construcción de la ciudad informal subyace una fuerte tensión entre los principios normativos y ciertos criterios de legitimidad que responden a legalidades alternativas propias de los espacios urbanos que surgieron mediante tomas de tierras (Rincón, 2006). Vale la pena reiterar que la expansión de la informalidad no trae consigo la total sustitución del orden jurídico formal; por el contrario, los criterios de legitimidad se traslapan con el orden jurídico

6 Los escándalos recientes más graves se produjeron en 2015 cuando, como consecuencia de múltiples denuncias de asignación y ventas ilegales de tierras y/o viviendas, la justicia ordenó una serie de allanamientos en la Secretaría de Tierras de la Municipalidad y en el IPV (Bachiller et al., 2015). 
formal. Incluso cuando el orden jurídico es infringido en la formación del hábitat popular, siempre termina apareciendo en las representaciones de los sujetos, para así orientar sus prácticas y expectativas (Azuela, 1993).

Los criterios de legitimidad evolucionan de acuerdo a la temporalidad y el grado de consolidación de la toma. En ocasiones puntuales, los criterios de legitimidad subvierten los supuestos básicos sobre los cuales gira el sistema normativo de acceso al suelo urbano. Dicha situación es especialmente visible en la primera etapa de la toma, cuando los ocupantes justifican su accionar remarcando la necesidad de contar con un espacio propio. Es el momento de mayor disputa frente a las categorías estatales. Como ejemplo cabe citar una nota enviada por el líder de un asentamiento a las autoridades municipales, solicitando dejar de ser tildados como "enganchados" para pasar a ser reconocidos como vecinos. En la entrevista que le realicé a dicho referente, sucedió algo similar con las nociones de ilegales y usurpadores: "Yo nunca digo que son ilegales, para mi por ahi pueden ser irregulares, como para darle un nombre, que uno ocupó un lugar irregularmente que no debería estar [...] en realidad el término usurpación siempre estuvo mal" (entrevista a Marcelo, 21 enero 2014).

Durante los inicios de la toma los criterios de legitimidad, como rebelión frente a las categorías normativas estatales, también se asocian con el esfuerzo mancomunado por transformar un "terreno vacío" en un "barrio"; entonces, la propia agencia es el elemento resaltado. Es otro momento de fuerte desafío a la lógica dominante articulada en torno a la propiedad, donde se retoman antiguas fórmulas radicales que proclaman "La tierra para quien la trabaja"; en esta instancia, el trabajo es representado como un elemento mágico capaz de transformar las propiedades de los territorios (el "espacio vacío" se convierte en "barrio") y el significado de las acciones sociales (la toma deja de ser un acto ilegal y pasa a ser leída en clave positiva).

Dijimos: nosotros nos vamos a poner las pilas. Si el gobierno no nos da, vamos nosotros a comprar cables. ¿Viste la instalación de los postes? Los pusimos nosotros, los cables los tra- jimos nosotros, y lo hicimos con un electricista que lo trajimos nosotros, y fuimos en masa a colgarnos y que el laburo sea lo más parecido a la Cooperativa (de Luz). Nosotros hicimos el laburo, el agua igual, nosotros... todos pala y picota. Todo lo que hoy ves lo hicimos nosotros. $Y$ no estoy hablando de un día, sino de meses, de años (entrevista a Eduardo, 11 septiembre 2012).

Significativamente, cuando consulté a estas personas si aceptarían ser relocalizadas, una de las condiciones que la mayoría planteó fue un resarcimiento económico por el trabajo realizado, entendiéndolo como un reconocimiento de los derechos sobre lo construido; así, estos discursos reconocen la ilegalidad del acceso al lote, pero la misma es contrastada con la legitimidad de la propiedad de la vivienda que construyeron. Tal como afirma Canestraro (2009), las mejoras realizadas en los terrenos y/o la gestión de diversos servicios (luz, gas) constituyen argumentos que posicionan distintivamente a los ocupantes, evidenciando la construcción de normativas tácitassociales que, en ocasiones, desencadenan en legalidades alternativas a las reconocidas oficialmente por el Estado.

No obstante, las representaciones sociales más desafiantes suelen diluirse a medida que la toma se consolida y el espacio se urbaniza. Entonces, el discurso de la propiedad y la legalidad prevalece sobre el de la necesidad y la legitimidad, llegando incluso en muchos casos a descalificar a partir de la ilegalidad a quienes inician nuevos procesos de ocupación de tierras. No casualmente en esta etapa uno de los reclamos más importantes consiste en la regularización del lote, a su vez asociada con la obtención de un título individual de propiedad. En resumen: las tomas de tierras poseen una dimensión política marcada por la tensión constante entre el orden y el conflicto, entre las pulsiones contestatarias y la voluntad de institucionalizarse. Por un lado, en las primeras etapas de la toma, cuando el objetivo es garantizar el derecho a la ciudad, se observa un discurso que, si bien reconoce la propiedad, identifica el suelo urbano y la vivienda como un bien social antes que como una mercancía; por el otro, cuando la toma se va consolidando en forma de barrio, el reclamo al 
Estado se expresa en el reconocimiento de los derechos de propiedad individual sobre el sitio.

Por lo general, los criterios de legitimidad son una expresión del modo en que el sentido común hegemónico se espacializa localmente; una vez más, la propiedad es un principio articulador básico en tal sentido. Así, muchos justificaron la legitimidad de sus actos alegando que no ocuparon tierras, sino que compraron la vivienda ("las mejoras") o el lote donde residen (a quien previamente había "usurpado"). En la mentalidad de estas personas, la ausencia de un título de propiedad puede ser significativa a nivel de futuros problemas legales, no así en cuanto a la legitimidad de sus actos. Tal como afirma Canestraro (2009), la disposición a la compra los coloca fuera del espacio del delito. En la misma dirección, Azuela (1993, p. 148) sostiene que "la legitimidad que suele tener la propiedad privada es lo que a su vez otorga legitimidad a la posesión que adquieren los pobladores" (p. 148). De modo similar, los informantes recurrentemente mencionan su intención de comprar en cuotas el lote "usurpado" a la municipalidad; Merklen (2005) vincula dichos discursos con un proyecto de propiedad privada del lote en tanto imaginario de acceso a un estatus superior que otorga garantías de seguridad. La propiedad nunca termina de ser cuestionada, ni siquiera en las primeras semanas de las tomas, así como protagonizar una ocupación de tierras no supone desconocer o rechazar la legalidad oficial, la cual es definida en el marco de la propiedad. Quien participa de una toma frecuentemente anhela convertirse en propietario. En el mismo sentido, a lo largo del trabajo de campo los residentes de los asentamientos también destacaron cómo, incluso estando conectados clandestinamente a la red eléctrica, se organizaron para pagar conjuntamente a la empresa suministradora el consumo y la instalación formal del servicio. Más aún: esta gente suele sostener que sus malestares se acabarán cuando se "regularice" su situación. Según dicha concepción, la recualificación municipal de la zona (de asentamiento a barrio) tendría efectos mágicos, pues el simple acto administrativo revertiría las fuentes de sus sufrimientos. La regularización opera como un rito de pasaje hacia la plena ciudadanía; así, la referente de una manzana sostenía su voluntad de pagar el derecho de ocupante en estos términos: "Si pagamos, se acaba el tilde que nos ponen de usurpadores" (entrevista a Karina, 18 noviembre 2012).

Los principios de legitimidad también varían en función del régimen de titularidad y el tipo de uso de la tierra ocupada. En la cosmovisión local, la ocupación de áreas vacantes no merece demasiada condena, mientras que, si en la zona se verifica la presencia de un propietario, el repudio es automático. Del mismo modo, el rechazo es superior cuando las tomas se generan en tierras de titularidad privada respecto de las fiscales:

En realidad, el término usurpación siempre estuvo mal. La usurpación es cuando se entra en una casa o cuando hay un terreno privado y uno va y rompe los portones y entra; ahi está usurpando porque tiene un propietario. Nosotros en este caso no rompimos nada, porque era campo, era un terreno municipal. $Y$ en realidad no es municipal, sino que es de Comodoro el terreno, era de todos los contribuyentes de Comodoro (entrevista a Marcelo, 21 enero 2014).

Otra manera de mitigar el peso de la legalidad invocando un principio de legitimidad se observa en los carteles colocados en el frente del lote ocupado, en los cuales se detalla el apellido de la familia y el número de expediente tramitado ante la Secretaría de Tierras solicitando un terreno. Los funcionarios municipales son especialmente críticos ante dichas prácticas: "Se creen que por tener un expediente tienen derecho a tomar. No esperan la resolución. Un expediente no da derecho, es solo el inicio de una solicitud" (entrevista a funcionario de la Secretaría de Tierras, 4 agosto 2012). Por el contrario, en la mentalidad de quienes ocuparon un terreno, el haber iniciado una solicitud de tierras otorga cierta legitimidad al reclamo: el expediente denota cómo, frente a la inacción y/o lentitud estatal ante una necesidad acuciante, la gente se vio forzada a actuar por sus propios medios tomando tierras. Para los usos nativos, se trata de una forma alternativa de legitimidad que discute con los criterios de legalidad imperantes. El número de expediente posee una fuerte carga simbólica, representa la pertenencia a la ciudad a partir de la apropiación de un espacio; da cuenta de que 
el sujeto antes de tomar un terreno apeló a la vía institucional para resolver su problema habitacional, resalta la posible transformación del estatuto legal del lote (en proceso hacia la legalización). Invocar un número de expediente es expresar que el sitio es de alguien, o que está en camino de serlo.

La ilegalidad se potencia cuando se superpone con ciertos discursos discriminatorios y xenófobos. Como en otros sitios del país, en Comodoro los estigmas que condenan a quienes protagonizaron tomas de tierras suelen combinarse con imaginarios raciales y étnicos; se trata de dimensiones que exceden a la propiedad y que se asocian, entre otras cuestiones, con el tiempo y la antigüedad de estadía en la ciudad. A pesar de la masiva presencia de argentinos en los asentamientos, las acusaciones recaen en los extranjeros como únicos responsables de las ocupaciones. Como se sostuvo anteriormente, estos imaginarios fueron fomentados mediante intervenciones puntuales, como las distintas ordenanzas municipales que impidieron el acceso a la tierra fiscal a los extranjeros o las notas del periodismo local más sensacionalista. Consecuentemente, no es de extrañar la masiva presencia de banderas argentinas en las casillas que conforman los asentamientos de Comodoro. Las mismas denotan una concepción donde la toma es, si no legitimada, cuando menos justificada, pues remite a un derecho diferencial de acceso a la tierra en función de un criterio de nacionalidad.

En relación directa con la ilegalidad, los estigmas también se expresan a partir de ciertas transgresiones a los códigos urbanos. En el caso de Cancha Belgrano en particular, los residentes apelan a un criterio de legitimidad basado en el entramado urbano regular, donde el asentamiento representa un esfuerzo por continuar con la lógica de la grilla de los barrios contiguos. En tal sentido, en más de una ocasión los pobladores de Cancha Belgrano remarcaron con orgullo la peculiaridad de su espacio residencial, el cual sería "el único asentamiento de la ciudad que respeta el entramado urbano" (entrevista a Eduardo, 11 septiembre 2012). Según estas personas, dicho "esfuerzo por hacer las cosas bien" sería uno de los argumentos centrales que permitirían la regularización del asentamiento en un futuro próximo.
Anteriormente se mencionó que la noción de necesidad es uno de los ítems más importantes en los procesos de constitución de criterios de legitimidad. Por sobre todas las cosas, la necesidad es definida en función de la capacidad económica de la unidad doméstica. La reproducción de la perspectiva hegemónica se observa en la siguiente nota, donde los vecinos de Cancha Belgrano apelaron a las categorías normativas estatales al dirigirse a la Secretaría de Tierras solicitando la instalación del servicio eléctrico; en la misma, se asume que la toma es un acto repudiable, pero simultáneamente se la justifica en función de un criterio de necesidad.

\section{Nosotros en este momento nos hacemos cargo de nuestra ilegalidad, pero a su vez queremos demostrarle con hechos y esfuerzos que real- mente el espacio ocupado ilegalmente lo ne- cesitábamos. Somos algunas pocas familias de clase media-baja y por eso es que a fines del año 2008 usurpamos en un espacio donde no habia nada absolutamente (vecinos del Macizo 48 Número 74, 23 febrero 2011).}

Los informantes frecuentemente destacaron que no habían formado parte de tomas previamente. Para estas personas, la participación en otras ocupaciones contradiría sus discursos basados en un principio de necesidad. Por otra parte, la necesidad desemboca en un relato que remarca el sufrimiento, recordando las condiciones de precariedad en las que vivían antes de la toma, pagando un alquiler que insumía un porcentaje desproporcionado de sus salarios, etcétera. En los jóvenes, el factor destacado son las tensiones ligadas al hacinamiento en el hogar de algún pariente luego de haber formado la propia familia. A su vez, los residentes del asentamiento suelen evocar las dificultades que debieron afrontar durante los primeros meses de la toma, residiendo en carpas o en "ranchos", soportando las inclemencias del clima patagónico; en palabras de un informante:

[E]star en un asentamiento es para gente de valor [...] porque está bien, no compramos un terreno, pero lo pagamos con el sufrimiento, lo pagamos con el coraje de resistir, con el coraje de armar una casa desde abajo y no saber si al otro dia vienen y te la tiran (entrevista a Eduardo, 11 septiembre 2012). 
La necesidad y el sufrimiento se potencian hasta límites insospechados cuando en los relatos se filtra la presencia de sus hijos. Significativamente, incluso los funcionarios municipales que adoptan una posición más intransigente frente a los asentamientos frenan sus argumentos al sostener la imposibilidad de desalojar una vivienda habitada por nińos.

Pero los criterios de legitimidad con los cuales los residentes de los asentamientos intentan revertir los estigmas que los descalifican en tanto ilegales no necesariamente presuponen una lógica inclusiva. Tales discursos nativos no desmontan el sentido común hegemónico; por el contrario, lo más frecuente es que repliquen los estereotipos en un "otro". A modo de ejemplo, quienes son desacreditados como ilegales intentan mitigar dichas acusaciones apelando a la necesidad, ligando la misma con la pobreza; por consiguiente, quienes tomaron tierras y poseen un empleo en el mundo del petróleo suelen ser seńalados acusadoramente (con su nivel de ingresos la necesidad desaparece y la toma se deslegitima). Algo similar ocurre con las banderas nacionales que flamean en los frentes de sus moradas: mediante las mismas, quienes son acusados como usurpadores intentan salvar su propia imagen recordando su derecho al acceso a la ciudad en tanto argentinos; no obstante, dichas medidas no mitigan, sino que refuerzan, las acusaciones que responsabilizan a los inmigrantes por las ocupaciones masivas. Bajo la misma lógica fueron repudiados quienes vendieron el terreno y se trasladaron a otro sitio. Si la compra y el comprador son percibidos positivamente (hay una voluntad de pagar, de ser consumidor, y ello parecería aproximarse a una concepción local del derecho), la venta y el vendedor son rechazados; para estos argumentos, la mercantilización del sitio ocupado (asociada con la compra y no con la venta) deslegitima cualquier posible discurso estructurado en torno a la necesidad. Estas observaciones coinciden con las de Cravino (2009), quien sostiene la legitimidad de la compra, la cual es percibida en una relación de continuidad con la ocupación y la necesidad, mientras que la venta se aproxima a la ilegalidad pues es concebida como un uso especulativo del suelo.
Por último, la conformación de los criterios de legitimidad se basa en una serie de imaginarios jurídicos que, a su vez, se articulan alrededor de representaciones específicas de la temporalidad. En el trabajo de campo, la temporalidad como dimensión relevante se materializó de diversas formas: en el texto se hizo referencia al sistema de puntajes de las ordenanzas municipales que regulan el acceso a tierras fiscales, se mencionaron categorías nativas basadas en la antigüedad de la residencia en la ciudad (tales como nacidos y criados o hijos del barrio). Por otra parte, y a contramarcha de lo que sostuvieron los seguidores de De Soto sobre la necesidad de implementar políticas de regularización, los deseos por obtener un título de propiedad en Cancha Belgrano por lo general no se expresaron como un modo de exorcizar el temor a un desalojo, sino que apuntaron a aspectos como la transmisión de un legado hereditario para los hijos. El tiempo de ocupación genera no solo sentido de pertenencia, sino que además constituye una relación de propiedad con el territorio; es decir, para estas personas, ser poseedores hasta cierto punto equivale a ser propietarios, y ello es así no por el título, sino por el uso prolongado en el tiempo (Rincón, 2006).

Tomando los conflictos como prácticas sociales que representan una oportunidad única para analizar las concepciones nativas sobre el derecho, el siguiente subtítulo gira en torno a la organización de los vecinos de Cancha Belgrano y su relación con la administración de los problemas inherentes a las disputas por la vivienda y el espacio barrial.

\section{Criterios de legitimidad y administración local de conflictos en Cancha Belgrano}

En un trabajo sobre las nociones de derecho durante las primeras etapas de conformación de una favela conocida como Passárgada, Souza Santos (1995) analiza los efectos tanto de la ausencia estatal como de clasificar un espacio como ilegal. En tal sentido, los residentes de la favela no pueden acceder o no intentan vincularse con las instituciones de regulación y control jurídico-territorial. Asimismo, cuando la policía ingresa a la favela es para realizar desalojos o razias indiscriminadas, mientras que la naturaleza clasista del aparato jurídico genera una distancia insalvable que se refuerza ante la situación 
de ilegalidad residencial. La siguiente anécdota etnográfica demuestra un proceso similar en Cancha Belgrano.

Las calles de Cancha Belgrano suelen encontrarse desiertas, ${ }^{7}$ pero una mañana me encontré con decenas de personas (la mayoría eran mujeres acompañadas con sus nińos, pues los hombres se encontraban trabajando) congregadas alrededor de un quiosco (el único comercio que funciona, aunque sin permiso municipal, en Cancha Belgrano). La reunión respondía al rumor de que en una casilla del asentamiento residía un abusador de menores. Entonces, un par de mujeres contó como el día anterior un grupo de policías les solicitó que oficiaran de testigos del allanamiento de la casilla, pero la búsqueda resultó infructuosa ya que el acusado no se encontraba en el lugar. Cabe aclarar que, en los cinco años de trabajo de campo, ésa fue la única oportunidad en la que supe de presencia policial en el asentamiento. En todo caso, durante las discusiones sobre cómo proceder, nadie propuso recurrir a la policía ni realizar una denuncia judicial. Por el contrario, una de las testigos afirmó que la policía fue la que sugirió tomar la medida que finalmente contó con el consenso generalizado: masivamente se dirigieron a la vivienda precaria; al llegar al sitio los pocos hombres presentes pasaron al frente, forzaron la puerta y, al constatar que se encontraba deshabitada, procedieron a incendiarla (algunos aprovecharon la ocasión para sustraer las escasas pertenencias del acusado).

Duhau y Giglia (2004) analizan la constitución de un orden urbano precario en este tipo de barrios, el cual se basa en normas convencionales antes que en reglas formales, operando a partir de la ambigüedad entre los límites de lo legal y lo legítimo. Estos investigadores se preguntan cómo es posible que, ante la ausencia de un Estado que imponga su ley, la violencia no estalle más frecuentemente en escenarios afectados por la permanente negociación de los códigos de convivencia. La respuesta que encuentran consiste en que el orden urbano alcanzado conlleva mecanismos que apuntan a evitar el con-

7 Debido al clima patagónico hostil y a la ausencia de espacios públicos, la sociabilidad en Comodoro Rivadavia suele generarse "puertas adentro". Pese a la precariedad de las viviendas, esta situación se refuerza en los asentamientos. flicto, prescribiendo altos niveles de tolerancia hacia los más diferentes usos del espacio público. Ahora bien, el respeto de un sinnúmero de acuerdos tácitos no elimina las condiciones propicias para el repentino pasaje de la tolerancia a la violencia. Los enfrentamientos entre vecinos suelen ser resultado de la colisión entre concepciones diferentes de urbanismo. Debido a la ausencia estatal, es muy común que estas disputas se resuelvan de manera violenta; más aún, la exacerbación de la propia agresividad responde a una lógica mediante la cual quien ostente una mayor capacidad de violencia será el triunfador de la contienda.

En Cancha Belgrano, el conflicto se articula en torno a cuestiones como el tratamiento de residuos ante la ausencia de un servicio oficial; vecinos que regularizaron su conexión al servicio eléctrico y deben pagar el consumo de otros que están conectados clandestinamente de su red; la apropiación particular de espacios que los demás residentes visualizan como comunes; los límites de cada lote, o la acusación de usurpación de un lote que había sido tomado previamente por alguien que no residía en el mismo, etcétera. Por otra parte, anteriormente se consideró cómo la ilegalidad se refuerza acoplándose con determinados discursos xenófobos. En el caso de Cancha Belgrano, desde sus orígenes este asentamiento creció como un espacio de y para argentinos; la organización vecinal no solo implicó reclamar al Estado servicios e infraestructura, sino también la expulsión violenta de los inmigrantes que intentaron afincarse en el asentamiento. Nuevamente, la declaración estatal de un asentamiento como ilegal supone serias dificultades para apelar al derecho positivo como vía de resolución de los conflictos; a partir de entonces, se instauran mecanismos extrajurídicos, muchas veces violentos, para dirimir las situaciones tensas.

En este tipo de escenarios urbanos, la organización de los vecinos puede derivar en instituciones locales encargadas de gestionar los conflictos barriales; a su vez, las nociones de derecho que subyacen en las prácticas y discursos de dichas organizaciones no siempre coinciden plenamente con lo dispuesto desde el derecho positivo. En Comodoro, las UV son la principal unidad territorial que representa a los habitantes de los barrios frente al Estado. El poder 
de las vecinales se vincula con su potestad de establecer quién merece ser considerado como vecino. Es lo que ocurrió en el barrio Abel Amaya, al interior del cual se localiza Cancha Belgrano. Cuando inicié mi trabajo de campo, el presidente de la UV se negaba a defender las demandas de "los ilegales" (así calificaba a los habitantes de los asentamientos localizados bajo su radio de influencia) frente a la municipalidad. En sus discursos se traslucía que un barrio no podía equipararse con un asentamiento, mientras que en la categoría de vecino solo podían ingresar quienes mostraban respeto por la propiedad privada. La mala disposición del presidente de la UV condujo a que los habitantes de Cancha Belgrano se organizaran y conformaran una auténtica vecinal paralela. La organización del asentamiento se articuló alrededor de una serie de delegados por manzana, de un referente que actuó a modo de intermediario con el Estado y de asambleas abiertas a todos los vecinos, donde se discutían cuestiones como las negociaciones con la empresa proveedora del servicio eléctrico, acuerdos en cuanto al tratamiento de los residuos, etcétera. Si bien el Estado durante años no reconoció oficialmente dicha organización, distintos líderes políticos con acceso a diversas dependencias estatales advirtieron en la misma un atractivo caudal electoral y facilitaron el acceso a ciertos servicios y recursos.

Es en este punto donde el caso de Cancha Belgrano toma distancia respecto de lo señalado por Souza Santos (1995). Antes que hablar de ausencia, en mi unidad de análisis sería más preciso señalar cómo el Estado se expresa a partir de la informalidad. De hecho, el Estado estuvo presente en el lento, sinuoso e incompleto proceso de urbanización del asentamiento; pero no fue mediante el reconocimiento de derechos de ciudadanía que se lograron las mejoras, sino que las mismas dependieron de la capacidad de organización y presión vecinal al sistema político, de la habilidad de su referente para negociar con ciertos líderes político partidarios y de la disposición a involucrarse en compromisos electorales.

En definitiva, en los barrios de la ciudad formal el nexo con el Estado se orienta a partir de un discurso de reconocimiento de derechos; por el contrario, en aquellos espacios que son tildados como ilegales, la urbanización depende de una vinculación con el
Estado basada en la subordinación, ingresando en terrenos que las ciencias sociales han examinado en términos de clientelismo. Lo que en los barrios "normales" de la ciudad se obtiene por defecto, por simple ciudadanía, en los asentamientos se reconvierte en una movilización y negociación permanente con el sistema político (Merklen, 2005).

\section{Reflexiones finales}

A lo largo del texto, se realizó una discusión crítica con las perspectivas hegemónicas que restringen la lectura de los procesos masivos de tomas de tierras a un simple acto jurídico ilegal. Más específicamente, el objetivo del artículo consistió en analizar los criterios de legitimidad que justifican los procesos de tomas de tierras, así como las modalidades de legalidad alternativas implícitas en tales criterios.

En el primer apartado del artículo se consideró el peso que la informalidad/ilegalidad históricamente tuvo en el crecimiento de las ciudades latinoamericanas. Las ciencias sociales llevan décadas reflexionando sobre la legalidad y el territorio; pese a la disparidad de los enfoques, no es casualidad que la propiedad haya sido un eje ineludible en la mayoría de los estudios. Ello es así pues los códigos normativos de nuestros países santifican a la propiedad privada como principal vía de acceso a la ciudad. A partir de entonces, el sistema jurídico configura un adentro y un afuera, generando territorios de ciudadanía plena o restringida, espacializando la ilegalidad en determinadas zonas de la ciudad. Ésta es la situación de los asentamientos: al no poder apelar a los mecanismos oficialmente reconocidos como vías legales de acceso a la vivienda, es decir, al mercado o al Estado, millones de personas de nuestro continente se ven forzadas a recurrir a la informalidad. Al definirlos desde la ilegalidad, el Estado promueve un modo específico de inserción urbana para los asentamientos que se encuentra determinado por la falta de derechos de ciudadanía, y que alienta relaciones de subordinación y clientelismo. El estatuto de ilegalidad genera una situación de inaccesibilidad estructural a los mecanismos oficiales de ordenamiento y control social. Es por ello que en tales territorios suelen surgir mecanismos informales internos de regulación social, a su vez asociados con prácticas normativas tácitas que poseen distintos niveles de conexión con la legalidad oficial. 
La multiplicidad de legalidades al interior de una misma ciudad responde a la heterogeneidad de los territorios que, a su vez, se articulan de distintas maneras alrededor de un vector clave como es la legalidad/ilegalidad (Souza Santos, 1995). En tal sentido, se sostuvo que el orden urbano no puede ser comprendido pura y exclusivamente a partir del análisis de las reglas formales, sino que se torna preciso examinar el peso de ciertas normas convencionales cuyo signo consiste en la ambigüedad entre los límites de lo legal y lo ilegal, lo legítimo y lo ilegítimo (Duhau y Giglia, 2004). La informalidad urbana se expande mediante complejas negociaciones cotidianas que, por otra parte, dependen de imaginarios sociales sobre el derecho. Si el territorio urbano es producto y producción de diversas prácticas y racionalidades normativas (Rincón, 2006), entonces la comprensión de la "ciudad informal" implica examinar las prácticas normativas paralelas al derecho que promueve el Estado.

En la segunda sección se argumentó que el Estado es el gran promotor de la informalidad urbana. Se sostuvo que la ilegalidad no es un ejercicio privativo de los sectores populares; por el contrario, grandes empresarios se apropiaron recientemente de tierras fiscales, las clases medias consiguen viviendas oficiales destinadas a los sectores populares gracias a sus contactos políticos, mientras que el propio Estado viola la legalidad con cierta recurrencia. Tomando el caso comodorense como ejemplo, en este apartado se hicieron operativos los argumentos centrales planteados en el encabezado anterior. Las tomas de tierras pasaron entonces a ser contextualizadas a partir de las dificultades de acceso al suelo urbano que aquejan a los sectores populares. Por consiguiente, la sección proporcionó datos sobre los precios exorbitantes del mercado inmobiliario y las falencias estatales en materia de construcción de viviendas. Del mismo modo, se planteó una correlación entre los booms petroleros, las etapas de fuerte crecimiento urbano y la expansión de la informalidad bajo el formato de las tomas masivas de tierras. También se señaló a la Municipalidad de Comodoro Rivadavia como el principal promotor de una lectura donde la toma de tierras es definida como un acto jurídico ilegal. Es el Estado el que, junto a los medios de comunicación, construye un sujeto moral al cual etiqueta como ocupante o usurpador. Asimismo, la Municipalidad de Comodoro regula el acceso al suelo fiscal mediante ordenanzas centradas en la antigüedad de la residencia en la zona; estas medidas, combinadas con los valores del mercado inmobiliario, incentivan prácticas ilegales como las ocupaciones de tierras por parte de los recién llegados a la ciudad.

El tercer apartado consistió en un análisis empírico sobre los criterios de legitimidad a los que apelan quienes protagonizan una ocupación de tierras. Dichos criterios de legitimidad fueron tratados como una forma de lidiar con los discursos que descalifican a estas personas como usurpadores. Cuando reconocemos que la ciudad es producida por diversos urbanismos, lo que el Estado denomina como ilegalidad puede reconvertirse en ciertos criterios de legitimidad. Estos criterios evidencian un urbanismo tácito que se presenta en una relación tensa con los principios legales. En tal sentido, llegamos a una conclusión similar a la de Souza Santos (1995), quien remarca la existencia de una "ambigüedad profunda de la conciencia popular del derecho en sociedades caracterizadas por grandes diferencias de clase" (p. 9): por una parte existe un imaginario del derecho como expulsivo, asociado con lo establecido por el código; por otra, se observa otra forma de derecho más justo, que habilita criterios de legitimidad basados en la satisfacción de necesidades fundamentales, así como en la acción colectiva y transformadora del territorio.

Entre los protagonistas de las tomas, las nociones de derecho surgen de forma conflictiva y oscilan según las coyunturas entre una serie de polos: la necesi$\mathrm{dad} /$ propiedad y la legitimidad/legalidad. Más aún, las ocupaciones de tierras poseen una temporalidad propia, y dichas contradicciones se inclinan hacia uno de los extremos en función de la evolución de los asentamientos. Así, en las primeras etapas de la toma frecuentemente los ocupantes justifican su accionar remarcando la necesidad de contar con un espacio propio. Ello no supone desconocer o rechazar la legalidad oficial, la cual es definida en el marco de la propiedad; por el contrario, la legalidad es reconocida como válida cuando, por ejemplo, se recuerda la propia intención de pagar por la tierra o por los servicios, desligándose así del mote de usurpadores. Sin embargo, en las etapas iniciales de la ocupación, 
la legitimidad de la necesidad suele ser privilegiada por sobre la legalidad de la propiedad. En cambio, a medida que la toma se consolida, se obtienen los servicios urbanos y el "asentamiento se transforma en barrio", el discurso de la propiedad y legalidad prevalece sobre el de la necesidad y la legitimidad llegando incluso, en muchos casos, a descalificar a partir de la ilegalidad a quienes protagonizan nuevos procesos de ocupación de tierras.

Existe una dimensión política en los diversos, y a veces conflictivos, sentidos de derecho que se manifiestan en estos espacios urbanos. Tal dimensión política supone entender el derecho como un campo de controversias, como una tensión constante entre el orden y el conflicto. Es decir, el derecho es definido de modo diferente por los procesos de gobierno respecto de los procesos de disenso. Si los primeros entienden el derecho en función de un lugar asignado y reconocido por el orden establecido, los procesos de disenso lo redefinirán como una disputa por el lugar, un cuestionamiento sobre quién tiene cabida en la comunidad (Arditi, 2011). En el primer ejemplo se localizan los funcionarios municipales, quienes limitan el derecho según criterios normativos; mediante apelativos como el de usurpadores, sus discursos conllevan la expulsión de quienes no son contabilizados como parte (las personas que, al no lograr responder al régimen de propiedad imperante, se ven forzadas a residir en una zona calificada como ilegal). En el otro espacio social se ubican los residentes de Cancha Belgrano, quienes defienden colectivamente su derecho a la ciudad invocando un discurso estructurado en torno a la necesidad, a su vez basado en la legitimidad antes que en la legalidad. La tensión existente entre pulsiones contestatarias y la voluntad de institucionalizarse, propia de los procesos de subjetivación política, supone entender al disenso como la aspiración por obtener un lugar socialmente reconocido; en este caso, el reconocimiento se ligaría con un proceso de regularización e integración urbana. Simultánea e implícitamente, al alzar sus voces estas personas cuestionan qué significa el derecho, la justicia, cuando hay partes que no han sido contempladas. En las tomas de tierras, dicha tensión aparece claramente en las concepciones sobre la noción de propiedad: por una parte, se observa un discurso radical que resalta el valor social de la vivienda por sobre su definición como una mercancía; esto ocurre especialmente en las primeras etapas de la toma, cuando el objetivo es garantizar el derecho a la ciudad. Por otra, cuando la toma se va consolidando y el asentamiento muta hacia el barrio, el reclamo al Estado se expresa en el reconocimiento a los derechos de propiedad individual sobre el sitio.

En la etnografía se detectaron otros criterios de legitimidad asociados con la ocupación de tierras: la necesidad como un argumento central (se resalta el tener hijos pequeños o el sufrimiento entendido como una experiencia prolongada de padecimientos en materia habitacional); el haber comprado el espacio residencial (pese a que quien lo vendió no tenía un título que acreditase la propiedad); el derecho diferencial a la tierra por ser argentinos; el haber iniciado un expediente solicitando un lote; etcétera. A su vez, se afirmó que los criterios de legitimidad no siempre se inscriben en un horizonte inclusivo. Por el contrario, los criterios de legitimidad resignifican las nociones formales de derecho, sin que ello suponga necesariamente cuestionarlas. En tal sentido, la lógica mediante la cual estas personas intentan salvarse de las acusaciones que las señalan como ilegales frecuentemente conlleva apelar a un criterio de legitimidad para el propio caso, aplicando simultáneamente el peso de la ley en otras personas que padecen un proceso de exclusión residencial similar. Es lo que ocurre con el criterio de necesidad, el cual redime a quien lo invoca sacrificando a su vez a otro identificado, por ejemplo, con "los petroleros"; el mismo mecanismo opera con las banderas que se colocan en el frente de los lotes, pues éstas amparan a un ocupante argentino en detrimento de los inmigrantes que también tuvieron que tomar tierras para resolver sus problemas habitacionales.

$\mathrm{Al}$ interior del último apartado, y siempre con relación a la retirada estatal de una zona declarada como ilegal, se propuso un encabezado basado en el análisis de las concepciones nativas del derecho e implícitas en la administración local de los conflictos. Entonces, se sostuvo la existencia de un orden informal capaz de gestionar la vida social y mitigar la intensidad de los conflictos inherentes a la apropiación y uso de una espacialidad barrial que no es cotidianamente regulada por parte del Estado. La ciudad informal se desarrolla mediante una serie 
de consensos, gracias a un urbanismo tácito. No obstante, en situaciones específicas, los acuerdos se rompen, o diferentes concepciones sobre la espacialidad entran en confrontación; en tales circunstancias, la ausencia de regulación estatal puede derivar en la resolución violenta del conflicto.

Cuando el fenómeno de la toma masiva de tierras se interpreta en términos jurídicos, el debate suele reducirse a una dicotomía entre "buenos vecinos" y "usurpadores". De tal modo, quedamos atrapados en una encrucijada que nos desvía del que debería ser el eje de la discusión: el carácter estructural del fenómeno, su conexión con el mercado inmobiliario y del trabajo, las políticas públicas en materia de suelo urbano y vivienda, o las clasificaciones estatales que etiquetan determinados espacios y/o a sujetos como ilegales. Por otra parte, y a modo de hipótesis de trabajo, en las reflexiones finales planteo que tal vez sea más productivo pensar estos fenómenos en términos de conflicto urbano antes que apelando a nociones como la de derecho a la ciudad. Es comprensible y valorable la dimensión reivindicativa del concepto de derecho a la ciudad, su propuesta por subrayar una legalidad más amplia e inclusiva, privilegiando el derecho natural por sobre el positivo, recordándole al Estado sus omisiones. No obstante, esta noción también puede reforzar la mirada estatal en función de la cual determinadas poblaciones, especialmente los extranjeros, son calificadas como ilegales. Asimismo, orientar la discusión en términos de derecho a la ciudad en ocasiones conduce a lecturas románticas que visualizan resistencias y movimientos sociales donde no necesariamente los hay. Cuando ello sucede, la perspectiva del derecho a la ciudad dificulta comprender la complejidad de los procesos sociales y los puntos de vista nativos, donde la gente que al comenzar una toma resalta el valor social de la vivienda luego redirecciona sus objetivos en pos de conseguir un título individual de propiedad. En tercer término, la potencialidad de un enfoque basado en el conflicto urbano antes que en el derecho a la ciudad nos recuerda que la urbanización de los espacios que son clasificados estatalmente como ilegales por lo general no responde a un reconocimiento de derechos, sino a la organización y capacidad de presión vecinal frente a las dependencias estatales. Por último, el derecho a la ciudad ha sido un concepto muy fructífero en su aspecto reivindicativo; no obstante, habiéndose puesto de moda, su uso masivo plantea dudas sobre el provecho que podemos obtener desde el ámbito académico al adoptarlo como dimensión analítica.

El tándem ilegalidad/propiedad se ha arraigado en el sentido común. Si pretendemos encontrar soluciones al problema del acceso al suelo y a la vivienda, debemos ampliar un espectro de posibilidades que, hasta el momento, hemos limitado a la propiedad individual de la tierra. Tal como sostiene Rincón (2006),

[...] uno de los problemas para tratar de entender el fenómeno de la ilegalidad en su expresión territorial, es el ensimismamiento en la cultura jurídica liberal y la tradición civilista dominante en la regulación territorial y la propiedad urbana [...] Poco se discute que la norma se estructura en base al derecho de propiedad (p. 681).

Desnaturalizar el sentido común conlleva comprender la propiedad privada como una relación social (Azuela, 1993), así como desplazar el eje de las discusiones de un análisis jurídico a otro sociológico.

\section{Referencias citadas}

Abramo, P. (2009). O mercado informal de solo em favelas e a mobilidade residencial dos pobres nas grandes cidades: um marco metodológico. En Abramo, P. (Coord.). Favela e mercado informal: a nova porta de entrada dos pobres nas ciudades brasileiras (pp. 14-47). Porto Alegre: Coelcao Habitare/Finep.

Arditi, B. (2011). El reencantamiento de la política como espacio de participación ciudadana. En Hopenhayn, M. y Sojo, A. (Comps.). Sentido de pertenencia en sociedades fragmentadas (pp. 55-84). Buenos Aires: Siglo XX.

Azuela de la Cueva, A. (1993). Los asentamientos populares y el orden jurídico en la urbanización periférica de América Latina. Revista Mexicana de Sociología, 55(3), 133-168.

Bachiller, S., Baeza, B., Vázquez, L., Freddo, B. y Usach, N. (2015). Hay una ciudad informal; o la atendés o no 
la atendés... En Bachiller, S. (Ed.). Toma de tierras y dificultades de acceso al suelo urbano en la Patagonia central. Buenos Aires: Miño y Dávila y UNPAedita.

Baeza, B. y Grimson, A. (2013). Desacoples entre el nivel de ingresos y jerarquías simbólicas en Comodoro Rivadavia. Acerca de las legitimidades de las desigualdades sociales. Revista Maná: Estudios de Antropología Social. PPGASMuseo Nacional.

Canestraro, M. L. (2009). Acerca de la fetichización de las normas: reflexiones sobre un conflicto por la apropiación del espacio urbano. Revista Question, 1(24). doi: http://perio.unlp.edu.ar/ojs/index.php/question/article/ view/866/767

Canestraro, M. L. (2011). ¿Ser o no ser propietario? Notas en torno a la regularización de asentamientos precarios. En Bolívar, T. y Erazo Espinoza, J. (Coords.). Dimensiones del hábitat popular latinoamericano. FLACSO Ecuador y CLACSO, Quito. doi: http://bibliotecavirtual. clacso.org.ar/clacso/gt/20120410103833/gthi2-20.pdf

Casabona, V. y Gúber, R. (1985). Marginalidad e integración, una falsa disyuntiva. En Bartolomé, L. (Comp.), Relocalizados. Antropología de las poblaciones desplazadas (pp. 145-164). Buenos Aires: IDES.

Catenazzi, A. y Reese, E. (2010). Derecho a la ciudad. Revista Voces en el Fénix, 1(1), junio. doi: http://www.vocesenelfenix.com/sites/default/files/pdf/13catenazzi_1.pdf

Clichevsky, N. (2004). Dos desafíos pendientes: la seguridad de la tenencia y los mercados de tierra para la vivienda social. Cepal, 2 (31 de diciembre). doi: http://www. cepal.org/pobrezaurbana/docs/boletin/analisis $\% 20$ de\%20coyuntura\%20b2.pdf

Cravino, M. C. y Fernández Wagner, R. (2006). Cuestionario a Raúl Fernández Wagner y María Cristina Cravino en vísperas del seminario en la UNGS. Café de las ciudades, 5(49), noviembre. doi: http://www.cafedelasciudades.com.ar/politica_49_2.htm

Cravino, M. C. (2009). El nuevo horizonte de la informalidad en el Área Metropolitana de Buenos Aires. En Abramo, P. (Coord.). Favela e mercado informal: a nova porta de entrada dos pobres nas ciudades brasileiras (pp. 272-303). Porto Alegre: Coelcao Habitare/Finep.
Duhau, E. y Giglia, Á. (2004). Conflictos por el espacio y orden urbano. Estudios Demográficos y Urbanos, 56, 257-288.

El Patagónico (2016). Entre la estigmatización y la carencia: en Comodoro hay cerca de 3000 ocupaciones de tierras. 28 de agosto. Recuperado de http://www.elpatagonico. com/entre-la-estigmatizacion-y-la-carencia-comodorohay-cerca-3000-ocupaciones-tierras-n1506305

Fava, R. (2014). La clase media, entre la historia y la cultura. Representaciones sociales sobre los vecinos en el conflicto con los ocupantes durante la toma del Parque Indoamericano. En Cravino, M. C. (Org.). Derecho a la ciudad y conflictos urbanos. La ocupación del Parque Indoamericano (pp. 87-111). Buenos Aires: Universidad Nacional de General Sarmiento.

Fernandes, E. (2008). Consideraciones generales sobre las políticas públicas de regularización de asentamientos informales en América Latina. EURE, 34(102), 25-38.

Merklen, D. (2005). Pobres ciudadanos. Las clases populares en la era democrática (1983-2003). Buenos Aires: Gorla.

Núñez, P. (2010). Arreglos locales y principios de justicia en pugna. Estudio de caso en un asentamiento del sur del Gran Buenos Aires. En Kessler, G., Svampa, M. y González Bombal, I. (Coords.). Reconfiguraciones del mundo popular. El conurbano bonaerense en la postconvertibilidad (pp. 223-272). Buenos Aires: Prometeo.

Ostuni, F. y Van Gelder, J. L. (2008). No sé si legal... ipero legítimo es! Percepciones sobre seguridad en la tenencia y títulos de propiedad en barrios informales del Gran Buenos Aires. En Cravino, M. C. (Org.). Los mil barrios (in) formales. Aportes para la construcción de un observatorio del hábitat popular del Área Metropolitana de Buenos Aires (pp. 201-230). Buenos Aires: Universidad Nacional de General Sarmiento.

Oszlak, O. (1991). Merecer la ciudad. Los pobres y el derecho al espacio urbano. Buenos Aires: Cedes, Humanitas.

Rincón Patiño, A. (2006). Racionalidades normativas y apropiación del territorio urbano: entre el territorio de la ley y la territorialidad de legalidades. Economía, Sociedad y Territorio, $\mathrm{V}(20)$, 673-702.

Salamanca Villamizar, C., Pizarro Astudillo, F. y Federle, J. (2016). Trayectorias de las (in)justicias espaciales en 
América Latina. Un estudio introductorio. En Bret, B., Gervais-Lambony, P., Hancock, C. y Landy, F. (Comps.). Justicia e injusticias espaciales (pp. 11-66). Rosario: Universidad Nacional de Rosario.

Souza Santos, B. (1995). El derecho en la Favela. Notas sobre la historia jurídico-social de Pasárgada. No hay Derecho, 6, 11-26. 